\title{
Horton Revisited: African Traditional Thought and Western Science
}

\author{
Lansana Keita*
}

\begin{abstract}
Over the years Robin Horton has argued for what he refers to as the 'continuity thesis' according to which there are theoretical similarities between African traditional thought and modern Western science. Horton's thesis stands in contrast to the standard Western anthropological appraisal of traditional African thought. The standard appraisal (Levy-Bruhl, Durkheim, Evans-Pritchard, et al.) stated that the two modes of thought were incommensurate. I argue that while the continuity thesis holds for certain aspects of African thought - empirical, protoscientific and metaphysical - it does not apply to traditional African religious expression. My thesis here is that belief systems founded on magic, religion and their combinations should be understood as belonging to what might be referred to as general metaphysics. I argue too that if the continuity thesis is to apply to the history of thought in Africa then the more apt comparison should be between the different phases of technological and scientific thought of the West. Thus Horton's claim that traditional African religious thought is configured according to the goals of explanation, prediction and control thereby putting it on the same epistemic plane as modern Western science is thereby rendered irrelevant. On the other hand the goal of traditional African religion like that of many other religious traditions - including those of the West - has principally been to seek a conscious communion with ancestors and anthropomorphised godheads and spiritual entities of the metaphysical realm.
\end{abstract}

\section{Résumé}

Au fil des ans, Robin Horton a soutenu ce qu'il appelle la « thèse de la continuité » selon laquelle il existe des similitudes théoriques entre la pensée

* University of the Gambia, The Gambia and BARA, University of Arizona, USA. 
Africaine traditionnelle et la science occidentale moderne. La thèse de Horton est à l'opposé de l'évaluation anthropologique courante en Occident de la pensée africaine traditionnelle. Selon cette évaluation courante (Lévy-Bruhl, Durkheim, Evans-Pritchard, et al.) ces deux modes de pensée sont sans rapport. Je soutiens que si la thèse de la continuité vaut pour certains aspects de la pensée africaine - empiriques, proto-scientifiques et métaphysiques - elle ne s'applique pas à l'expression religieuse africaine. Ma thèse démontre qu'il faut appréhender les systèmes de croyance reposant sur la magie, la religion et leurs mélanges comme appartenant à ce que l'on pourrait dénommer la métaphysique générale. Je soutiens également que si la thèse de la continuité doit s'appliquer à l'histoire de la pensée en Afrique, alors la comparaison la plus qualifiée doit se situer entre les différentes phases de la pensée technologique et scientifique en Occident. Ainsi l'argument de Horton selon lequel la pensée religieuse traditionnelle en Afrique est configurée en fonction des objectifs d'explication, de prévision et de contrôle, ce qui la place sur le même plan épistémologique que la science occidentale moderne, devient donc hors propos. D'autre part, la religion africaine traditionnelle comme biens d'autres traditions religieuses - y compris celles de l'Occident - a essentiellement pour but de rechercher une communion consciente avec les ancêtres et avec les divinités anthropomorphiques et les entités spirituelles du monde métaphysique.

\section{Introduction}

The expansion of Western Europe into other parts of the globe was no doubt partially caused by the Western European absorption of the intellectual patrimony of the ancient Greco-Egyptian world transported to Europe by way of the Islamic beachhead of Moorish Spain. The Renaissance is the name usually given to the ensuing paradigm shift in Western Europe founded on the critical episteme of the ancient Greco-Egyptian world. The Renaissance culminated in the European Enlightenment with its stress on rationality, empiricism, and an increasing opposition to metaphysics. The ideological role of this latter was to offer reasoned support for the principal claims of Western theology founded, ironically, on two thinkers from North Africa, Plotinus and Augustine. The increasing opposition to metaphysics no doubt stemmed from an increasing recognition that an empiricist approach to things was more efficacious for practical life than that afforded by metaphysical thinking. A paradigm founded on empiricist principles that sought to explain events in nature, expressed in the permanency of writing and quantitative measurement, offered a much greater cognitive and technological yield that any extant system of metaphysics.

It was the triumph of empiricism as made evident by an increasing embrace of the cognitive power and yield of a burgeoning science (then known as natural philosophy) that, translated into a rapidly improving technology, afforded Western Europe the tools to expand and impose its influence on 
other parts of the globe. On this basis Europe assumed to itself a novel identity of 'empirical rationality' founded on number, measurement and the printed word, all expressed in an increasingly effective technology. This technology included not only machines that aided humans in practical matters but also weaponry that supported the advancement of warfare.

Thus in time the technological advantages that Western Europe enjoyed over the rest of the world, including Africa, were seen to derive from the rational-empiricist cognitive paradigm that was the intellectual fruit of the European Enlightenment. The great cognitive transition in Europe occurred when theology was dethroned as the major explanatory discipline by those philosophers who were eventually seen as rationalists or empiricists. Descartes's rationalist methodology and Hume's critical empiricism all led eventually to the weakening of the central claims of theology in spite of its rationalist methodology.

At the time of the European Enlightenment the practice of religion as ritual by the non-intellectual public was not much threatened by the imminent intellectual transformations that were about to eventuate with regard to theology and philosophy. The practice of ritual Christianity by a minimally literate public was untouched by the intellectual wrestling about ontological proofs engaged in by the philosophers. Following Kant's systematic analysis of the structure of human reasoning, the central role that metaphysics played in the human quest to know and understand reality gave way to a scientific empiricism formulated according to the directives of critical thinking.

It was the Enlightenment that led not only to the eventual primacy of experimental physical science but also to the moral sciences which ultimately developed into the human and social sciences. Political economy, political philosophy, sociology and anthropology were all founded on the Enlightenment principle of critical reason coupled with empirical observation. Obviously, societies that did not conform to the intellectual principles of the Enlightenment were seen as intellectually backward. This point of view was easily buttressed by the technological advantages that Enlightenment society conferred on the nations of Western Europe. The upshot of this intellectual transformation for Western Europe was that reality was no longer to be viewed in terms of principles that supported a natural interaction between the material and non-material worlds. Cartesian dualism effectively established this principle. Henceforth, concepts that could not be empirically substantiated apart from those of pure mathematics and logic were to be relegated to the world of metaphysics. This world of metaphysics was then seen increasingly as the repository of items traditionally discussed in areas such as theology, moral philosophy and magic. 
But the Enlightenment mindset was so deeply entrenched at the time of the development of the discipline of anthropology that the anthropologists who studied non-Western societies were easily convinced that the modes of thinking of non-Western peoples, including Africans, were to be viewed as intrinsically erroneous because such thinking did not establish clear distinctions between ideas concerning the world of empirically confirmable events and those that did not. Despite the fact that non-Westerners operated with practical rationality in matters concerning the material world there were in many instances no strict lines of demarcation drawn between the sensory empirical world and its assumed metaphysical counterpart. Those familiar with the writings of the British philosopher, David Hume, will recall his recommendation that all texts on metaphysics should be, as he put it, 'committed to the flames'.

In short, the Enlightenment thesis arrived at the conclusion that genuine knowledge with cognitive content was restricted to the empirical world which was, for all practical purposes, inanimate. If an animate world existed it was relegated to a general realm that was the proper province of metaphysics. The inanimate world was the proper world to which those who sought genuine knowledge must restrict themselves. And inquiry into this world should be conducted by appeal to the proper principles of deductive reasoning as was found in mathematics and logic.

It is on this basis that post-Enlightenment European thinkers, having first invented the social science of anthropology to examine the cultures of the world's non-European peoples, sought to dismiss, for example, the thinking that justified African systems of belief as pre-logical or irrational. But this was more the stance adopted by those who approached the issue from a more theoretical angle. Those anthropologists who actually observed the practical life of African peoples recognised that the practical logic employed in this regard was indeed transculturally valid. Consider in this regard the respective debates on the ideas of researchers such as Lucien Levy-Bruhl and E.E. Evans-Pritchard respectively.

It was recognised too by the European theorists that the systems of thought of the peoples of Africa sprang mainly from a holistic world view. It was this feature of African thinking that prompted thinkers such as Placide Tempels to merge the spiritual world of Christian theology, as a branch of metaphysics, with the purported animist assumptions of holistic African thought. Yet in spite of all this, the explanatory and instrumental power of an epistemologically independent empirical science could not be challenged either by Christian theology or the holistic metaphysics of Africa.

Instrumental practices involving magic proved again to be no match for the principles of modern science. Out of all this there arose three schools of 
thought in the camp of the Western anthropologists: those who argued that the thinking patterns of the modern West were systematically incompatible with the traditional thinking patterns of Africa, those who thought that there could be some inter-cultural common point of reference on the issue of religious communication, and those who thought that there was indeed a certifiable cognitive bridgehead between African religious (cum metaphysical) thought and Western science. Robin Horton, among the latest in a long line of Western theorists who studied Africa from Enlightenment times, supported the third position. It is on this basis that his 1967 paper 'African Traditional Thought and Western Science' generated a great amount of interest just at the historic juncture of African decolonisation. Horton's paper is of historical interest because it attempted to argue for a position that hitherto had not been argued for: that there was a cognitively rational core that linked African traditional thought with the modern Western scientific paradigm. Horton's claim was that just as explanation, prediction and control were the rational goals of modern science, so too were these three requirements at the core of African traditional thought.

But what is the significance of this evolution in the evaluation of precolonial African thought in the history of ideas? The significance is that it offers some insights into the way in which Europe and Africa interacted with each other at the point of encounter not only at the practical level but also at the intellectual. The intellectual interaction was initially one-sided given the monopoly of appraisal that derived from the Western side. Hegel, Levy-Bruhl, Malinowski, Evans-Pritchard, Tempels, Gellner, et al., all had their say without equal African input and this helped shape the image of Africa throughout the colonial era until the spirited counterpoints from theorists such as Cheikh Anta Diop and Paulin Hountondji, both of whom responded to the then popular Western appraisal of African thought. In the same vein, one must also note the responses of African thinkers such as Senghor who adopted the views of Western theorists such as Levy-Bruhl and Frobenius. Thus, an appraisal of the work of Horton affords an appraisal of the trends in the evaluation of African modes of thought over time.

Before an actual evaluation of Horton's theories, I want to establish the framework in which the discussion will take place. The world as reflected in human thought consists of two realms: the material realm that is explored by practical observation and empirical science, and a non-empirical realm that, for purposes of convenience, can be referred to as the realm of metaphysics. The origin of the realm of metaphysics is as follows: when humans were unable to explain or control events in the material world, appeal was often made to explanations and control methods that existed in an assumed nonmaterial world. This theoretical world was populated not only with forces 
and entities that were assumed to be causally connected to the material world but also with conscious beings themselves, albeit in non-material form. The former elements belonged to the sub-realm of magic while the latter belonged to the other sub-realm of religion. Quite often both sub-realms were intertwined in their purported interaction with living humans in the material world. I believe that this distinction between the non-material human agents and non-material entities of the metaphysical world is important. The reason is that whereas the principles of explanation, prediction and control could be seen to apply equally to what scientists and metaphysicians of magic or alchemy seek this is not the case with regard to human interaction with their non-material counterparts in the metaphysical world. This is where religion distinguishes itself from other aspects of the world of metaphysics. The essential point about religion is that it constitutes a set of beliefs and practices whose main function is communication with kin folk who are deceased. These kin folk include not only departed ancestors but also anthropomorphic creators of all phenomena including humans. The function of religion as discourse is not really about explanation, prediction and control as Horton might argue but mainly about communication with spriritualised counterparts in the non-material world.

\section{Horton's continuity thesis}

Horton's 1967 paper argues that African traditional thought and Western science both share the same methodological goals of explanation, prediction and control. In the case of African traditional thought, Horton focuses especially on what he refers to as African traditional religion and in the case of Western science he refers to science as it is practiced in the modern West. According to Horton, 'down through the years, this article enjoyed a certain notoriety... [but] All in all, the responses to the article have been predominantly unfavourable. But they have continued in surprising profusion down to the present day' (Horton 1997: 310). In this regard, Horton makes pointed reference to Tambiah (1973) and Wiredu (1980) who respectively view his comparative study as 'Eurocentric or otherwise ill-conceived' (Horton 1997: 432). It was on account of the continuing response to the article that Horton chose to revisit its theme with 'Tradition and Modernity Revisited' (Horton 1997).

The significance of Horton's paper derives from the fact that it sought to place on the same methodological plane the modes of thinking involved in traditional African thought and those of the modern West. The dominant paradigm concerning African thought as expressed by Western anthropological theory was that African modes of thought in general were essentially incommensurable with the rational modes of expression that symbolised the cognitive patrimony of the West. Lucien Levy-Bruhl is well-known for his 
argument that the thought patterns of pre-modern people were pre-logical with their recourse to mysticism and superstition to explain phenomena (Levy Bruhl 1910, 1922). This thesis of Levy-Bruhl's later served as the theoretical template for the work of E. E. Evans-Pritchard in his anthropological fieldwork among the Azande of South Sudan (Evans-Pritchard 1937, 1956). What Evans-Pritchard noted was that in their mundane daily existence involving practical matters, the Azande employed commonsense thinking based on empirical observations. But it was his description of the thought processes of this ethnic group regarding their metaphysical explanations of events that was of epistemological importance to Western philosophers. The upshot of the discussion concerning Azande thought was that while it appeared to be cognitively incommensurate with modern Western thought it was cognitively consistent in its own conceptual universe. But what Evans-Pritchard's studies were seen to achieve was the maintaining of an implicitly essentialist theory of African traditional thought.

The effect of Horton's thesis in 'African Traditional Thought and Western Science' was to radically revise the then dominant Western paradigm concerning traditional African thought by arguing that there was an epistemological continuity between traditional African religious thought and modern Western science. The basic question that is posed by both scientific and religious theory is how should empirically observed phenomena, processes and events be explained? According to Horton, traditional African religious thought appeals to non-observable theoretical entities in much the same way that empirical science does. In this regard, traditional religious concepts such as spirits, gods and similar entities have as much ontological significance as the theoretical terms of contemporary physical science.

In the case of science, explanation for Horton involves a quest for the "elaboration of a scheme of entities or forces operating "behind" or "within" the world of common-sense observations' (Horton 1997:198). The total theoretical package makes sense because observed or sensed phenomena are linked to underlying non-evident occurrences by what philosophers of science call correspondence rules. The key question here of course is that concerning the reality or purely theoretical nature of the 'qualia' of theory. According to Horton, 'Perhaps the most up-to-date line is that there are good reasons for conceding the reality both of common-sense things and of theoretical entities' (198). What this establishes is a 'unity in duality uniquely characteristic of the relation between the world of common-sense and the world of theory' (198).

For Horton, the qualitative similarity between African traditional thought and modern science is that they both share the criteria required of any cognitive theory. According to Horton: 'if, however, we recognise that the aim of 
theory is the demonstration of a limited number of kinds of entity or process underlying the diversity of experience, then the picture becomes different' (199). The qualitative similarity between African traditional thought and modern Western science is to be explained by Horton's persistent claim that human intellectual interaction with the surrounding empirical world is motivated basically by three considerations - of prediction, explanation and control. Horton argues for what he regards as a continuity thesis between African traditional - its metaphysical aspects - thought and modern Western science. The explanatory assumptions of traditional metaphysics differ from their counterparts in modern science only in that the former are animate and anthropomorphised - as in the case of religion - while the latter are not. In this connection, Horton makes little distinction between African traditional religions, metaphysics and modern science.

In 'Tradition and Modernity Revisited', Horton points out that there have been basically three kinds of response to his 1967 article. There are those theorists who 'doubted the legitimacy of the comparative exercise itself' (306) on the grounds that modern and scientific modes of thought are most evidently epistemologically superior to traditional ways of thinking if only for their greater efficacy and pragmatic yield. In this regard, comparative studies of inter-cultural modes of thought are probably only of academic interest. Justification in this regard for Horton would derive from the fact that understanding of modernity is advanced by evaluating it from the standpoint of the traditional (306). Of more interest to Horton have been those whom he defined as 'Symbolists' and 'Fideists'. According to him, the Symbolists regard 'all religious life, whether traditional or modern, as a species of poetic jollification rather than as a system of theory and practice guided by the aims of explanation, prediction and control' (306). And the 'Wittgensteinian "Fideists" who like to think of all religious life as an expression of an autonomous commitment to communion with Spiritual Being, and again as something totally different from thought and action directed by the ends of explanation, prediction and control' (306). I am rather partial to the views of Horton's 'Symbolists' and 'Fideists'.

Horton sums up the ongoing debates concerning his original thesis in a 'Postscript' in which he defends what he refers to as his 'intellectualist' (1997:13) approach concerning African traditional modes of thought with his insistence that the central roles of explanation, prediction and control apply not only to modern science but also to religious beliefs. This is his basis for arguing not only in favour of the continuity thesis ('Tradition and Modernity Revisited', 1997:301-46) but also on behalf of the similarity thesis ('Postscript', 1997:347-48). As Horton puts it: 'If there is one thesis that unites the essays assembled in this volume, it is that of the deep-seated simi- 
larity between much of the world's religious thought, past and present, and the theoretical thought of the modern sciences' ('Postscript', 1997: 347).

\section{Metaphysics, religion, and science}

In what follows I intend to argue contra Horton that there are good grounds for justifying a distinction between religion, magic and the proto-scientific within the context of metaphysical systems. Despite the fact that all human systems of thought are ontologically unified in their quest to explain, understand and control relevant phenomena, in the area of traditional religion this intent is less concerned with epistemological concerns than with the emotive ones of communion with spiritual beings. Yet there is an area of traditional metaphysical thought which does conform to Horton's intellectualist paradigm of explanation, prediction and control. It is this area of human thought that eventually developed into theoretical empirical science by way of magic and alchemy. But I would not proceed along the lines of James Frazer's 'Golden Bough' hypothesis (Frazer 1967). Frazer argued that the progression of human thought could be defined according to three distinct temporal phases indicative of an ever-increasing intellectual maturation: magic, religion, then science. I do not accept this three stage approach because it seems to me that religion serves a special function in the psychology of humankind. Magic and science are concerned essentially with the explanation and manipulation of phenomena. Religion is concerned mainly with communication and maintaining kinship with departed ancestors and anthropomorphised beings in the form of deities or some single deity who is the source of all phenomena and on whom might be conferred a supra-human moral authority.

What I argue for is this distinction: properly scientific thought is committed to a paradigm of empiricism and non-scientific thought is committed to metaphysical modes of thinking. The realm of the metaphysical assumes that there are two kinds of world: the physical and the metaphysical. Both worlds are conjoined but the metaphysical exercises great influence on the physical. And even so, the metaphysical world mirrors the physical world in that the human elements of the physical world have their counterparts in the metaphysical world. This is the province of religious thought. The non-human elements of the metaphysical world are also correlated with the non-human elements, forces and agencies of the empirical world. But the key problem here, and where I have a problem with Horton's thesis, is that empirical science necessarily requires that its theoretical terms have actual empirical reference of some sorts. This is not a necessary and provable requirement for metaphysical claims. 
Horton claims that the reason why there is no justification for any qualitative distinction between the goals of scientific practice and traditional African metaphysical systems is that in both cases the aims of their respective practitioners are the same: explanation, prediction and control. This observation may be correct but it does no more than state an obvious fact. For the very elementary purposes of survival human thinking in all cultures is geared towards explanation, prediction, and control of all sensed phenomena.

In the essay 'Tradition and Modernity Revisited', Horton (1997:317) has sought to defend his original thesis of a 'closed-open' distinction between modern scientific paradigms and traditional thought systems by arguing that the 'closed-open' distinction is not to be as sharply assumed as in his previous research. What this more flexible paradigm has achieved is that 'it tends to produce and sustain a single over-arching theoretical framework rather than a multiplicity of such frameworks' (317). The result of this of course is to further reinforce Horton's continuity thesis. This thesis claims that the explanatory entities that modern science and traditional metaphysical systems invoke to explain primary phenomena belong to the same context. The intellectual intent in both cases is strictly pragmatic with efficacy of result being the ultimate goal. One might consider in this instance the classic case of the individual in a village society who first seeks a traditional cure for some illness, then after disappointment seeks treatment based on the findings of modern science. Repeated success with the latter route would tend to wean the villager away from the putatively ineffective traditional cures. The principle at work here is no doubt that of inductive inference. It is for this reason that especially in Africa's urban areas curative pharmaceutical products of all types are regularly purchased on the basis of their efficacy. One should note that in this regard no metaphysical explanations are sought to explain their curative powers.

But the gradual erosion in the belief in the efficacy of traditional predictive and explanatory cures has not led to widespread disaffection with religious belief. The reason for this derives from the distinction I make between explanatory systems that appeal to magic and religious systems in general. Horton's central point expressed as the similarity thesis is that since traditional modes of belief are formulated to answer questions of explanation, prediction and control, as is the case for the sciences, there is no genuine ontological basis to distinguish qualitatively between scientific and metaphysical modes of thought. Traditional African metaphysical systems include both religious systems whose main elements constitute spiritual beings with moral powers and influence, and holistic systems whose function is to explain the sensory world without the special considerations assigned to communication as in the sense of religion. 
But Horton's claim about explanation, prediction and control as being the goals of both scientific theory and religious systems is in itself a trivial claim about the psychology of human behaviour. For example, parents are fully concerned with the explanation, prediction and control of the behaviour of their young children. Similarly, any organised society is necessarily concerned with the explanation, prediction and control of its constituent citizens, usually by legal and cultural methods. Thus, one can point to a multiplicity of human practices and behaviours for which the goal is control of behaviour founded on the principles of prediction and control.

On the basis of the above argument, the central plank of Horton's continuity and similarity theses is cast in doubt. But this observation does not however question the fact that scientific and metaphysical theories both seek explanation, prediction and control of observed phenomena. In the case of science 'control' is specifically the task of applied science and technology; in the case of control metaphysics 'control' is in the hands of the shaman - in reality a pseudo-technologist - who attempts to explain some phenomenon, usually an illness or physical defect, by appeal to conscious or living suprasensory animate entities or spirits (Horton 1997).

But we should make a qualitative distinction between the animate explanatory phenomena of traditional metaphysical systems and foundational moral systems of belief enforced by personalised supra-sensory figures often known as deities. Purely in terms of its definitional terms the concept of religion has not been securely defined (Horton 1997:19-20). Horton finds the three standard definitions wanting and seeks to offer an alternative definition (Horton 1997: 19). Horton claims that his definition of religion is closer to that of Tylor's as 'belief in a certain kind of object, whether this be "spirits" or "the supernatural"' (Horton 1997: 23). He is more specific about religion when he writes: 'In short, religion can be looked upon as an extension of the field of people's social relationships beyond the confines of purely human society' (Horton 1997: 32). Thus the key element in Horton's definition of religion is the extension of the idea of human-to-human relationships to human-to-god relationships. And these relationships are, according to Horton, a combination of communion and manipulation (33). He states too that as scientific findings are established the manipulative aspect of religion 'will be continuously eroded while communion remains' (45).

Horton's position on the manipulation-communion thesis is at variance with that assumed by twentieth century empiricism founded on the assumption that only empirically testable beliefs can ever be candidates for serious epistemological validity. But the basis for this particular paradigm, according to Horton, is the epistemologically suspect principle of induction. Horton offers the standard critique of the principle of induction with the observation that no epistemological justification of induction is possible "which does not 
appeal to the very principles involved' (Horton 1993: 46). But he then makes the curious claim that the basis for human commitment to the principle of induction 'has causes deep in the roots of our nature, but which has no rationale; and as such its status is no different from a programme which accepts faith as sufficient ground for believing in god or gods' (46).

Horton's claim that the human acceptance of inductive inference has its origins in the human constitution is problematic and difficult to accept. It would seem that our adherence to the principle of induction derives rather from the nature of the sensorily-experienced material world dependent as it is on the past and present but not on the future. And while there are logically sound reasons for action and behaviour in this world based on inductive inference - reinforced with deductive modes of thinking - it is obviously cognitively problematic to apply a programme of faith to untestables. After all, a programme of faith must still be founded on some epistemological principle. And a programme of faith upheld on the basis of credo quia credo must appeal to some epistemological principle especially when it involves untestables.

It is on this basis that Horton is inconsistent when he claims that the individual who applies a 'single logical programme to all beliefs' is no more logically coherent than the individual who applies a 'second programme to beliefs about which the first can say nothing' (46). For Horton's epistemological framework is based on the idea of the similarity thesis. This thesis claims that explanation, prediction and control constitute the pragmatic designs behind religious practice and scientific investigation (328). Thus whatever differences that exist between traditional religions and modern scientific thinking are not to be taken as qualitative but should be seen rather as aspects of similar epistemological paradigms. Both traditional religions and modern scientific thought could be formulated as constitutive of primary and secondary theories. Primary theory is concerned to formulate in linguistically coherent terms the sensory macroscopic world while secondary theory explains this world in terms of programmes of prediction, explanation and control.

It is evident that explanation, prediction and control would not be possible without the positing of testable hypotheses. Yet Horton argues (46) on behalf of sustaining hypotheses that are founded on a non-uniform epistemology. A more accurate explanation of the past and ongoing epistemological conflict between metaphysics and empiricism is as follows: The history of human thought may be described as attempts to understand the sensory world in terms of the structure of phenomena as they exist in time. The sensory world presents itself to humans in myriad forms: forms that appear to be protean, forms that seem to be constant and static, and forms that interact 
with the human organism in ways that demand understanding, that is, explanation. Human pragmatism, effected along the lines of trial and error, has historically been the source of technology which in turn reflects particular levels of explanation and prediction. It was this essentially empiricist approach to sensory experiences that formed the basis for what later developed into scientific analysis.

What is most striking about the human cerebral structure is that it is unique among the cerebral structures of all organisms in its attempts to interpret and understand the sensory experiences presented to it in essentially holistic terms. It is this holistic approach to sensory experiences that has led to what has been called metaphysics. The function of metaphysics in the human quest for holistic understanding of sensory phenomena has been to offer ontological formulations to explain phenomena that defied empirical explanations. It is in the context of metaphysics that the non-empirical world became populated with non-visible but existent forces. But such forces could also be conscious.

It is instructive now to stress again that the domain of metaphysics consists of two qualitatively distinct spheres. There is the strictly ontological world of animate matter and phenomena which may be controlled by the operations of individuals who like modern technologists have ascribed to themselves the power to manipulate this metaphysical world so as to effect changes in the empirical world. It is this ontological world that has been absorbed by modern science and technology. Horton's similarity and continuity theses apply to this world only.

But there is also the other sphere of the domain of metaphysics that is occupied also by empirically untestable animate phenomena, but such phenomena are not just animate but also personalised. This sphere is populated by two kinds of personalised beings: departed ancestors and supernatural progenitors whose function is to establish ethical standards for the living and who ultimately offer an explanation for the purpose of life and existence itself. Such supernatural progenitors are generically referred to as gods and provide communion with humans essentially on moral terms. The relationship is purely ethical and has little bearing on the idea of explanation, prediction and control as it would apply in the case of a metaphysical or empiricist ontology.

The crucial function played by this metaphysical domain again may be explained by the human cerebral structure. Given that human behaviour is not motivated by instinct but by conscious decision-making which involves conscious choice and the socially founded ethical implications of such, ethics becomes therefore the cornerstone of human social life. It was natural in the course of human history for humans to cultivate a specific emotional 
attachment to their ancestors, an emotional attachment that became reified in ethical terms. Humans must necessarily have assumed that there was some first ancestor who was the original progenitor of all humans and all phenomena. In strictly practical terms the idea of a supernatural progenitor of individuals could be seen merely as idealisations of relationships that humans share with their parents from infancy to adulthood. The parent is seen as omnipotent, benevolent and the ultimate provider. It is the parent who establishes and enforces moral codes and rules. Proper conduct on the part of the child is rewarded while improper conduct is reshaped by various forms of operant conditioning. The child also expects the ideal parent to entertain requests for wishes, needs, and wants. The child as adult projects this model of child-parent relationship into an ideal world of a person-godhead relationship. The key element here is interactive communion instantiated with symbolic and ritual acts involving prayer, sacrificial offerings, votary offerings, and so on.

The principle discussed here applies equally to 'traditional African religions' as well as those of more universalist reach such as Christianity and Islam. It is in this sense that Horton's idea of the communion/manipulation aspect of human behaviour seems appropriate with regard to religion (Horton 1997). The key point made here is that contra Horton, religion - of whatever dimension - is an aspect of metaphysics but is distinct from ontological metaphysics, increasingly replaced by empirical science.

Given that the relationship of communion between the supernatural deity and humans is one of supplication, especially in times of perceived need, such dependence has been indeed reduced in those societies where recommendations of empirical science have proved to be more efficacious. Individuals suffering from some ailment in those societies that rely heavily on modern technology would preferably and initially seek cures founded on scientifically proven empirical procedures rather than those founded on the metaphysical mechanisms of prayer and other kinds of ritual offerings. But it should be noted that when cures founded on empirical science fail, alternatives, including prayer, are pursued.

But does the above analysis offer a fair treatment of metaphysics, a body of ideas that humans have appealed to ever since the dawn of humanity to provide cognitive closure to questions that were not answerable empirically? Metaphysics has survived in the areas of religion and theology despite the continuing advances of empirical science. I want to argue though that metaphysical thought maintains much allegiance only because of the way humans think. The human brain is structured not only to receive sensory information but also to seek explanations in terms of the principles of proximate and ultimate causation. In this regard the human mind is not just limited to 
receive sensory information from the empirical world. Thus if explanations in terms of ultimate causes are not provided by the empirical world the mind would tend to seek explanations from an assumed or imagined non-empirical realm. The tendency to seek non-empirical explanations would seem to be inversely related to the advances made by empirical science as is evidenced by an appraisal of the history of the growth of knowledge. It was on account of this that Immanuel Kant, a major philosopher of the European Enlightenment, was able to demonstrate that metaphysics was not a genuine source for knowledge. The human mind may crave metaphysical knowledge in its desire for ontological closure on the issue of 'being' but such knowledge remains limited to what could be empirically confirmable in a cognitively bracketed context. In this regard, the power and influence of metaphysics lay historically with religion and theology. The inroads of empirical science with its impressive empirical and technological yield are what transformed this situation. Religious thought from whatever cultural origin was increasingly seen, therefore, as being founded on human imagination prompted by the emotions. Science, by contrast, required mature and disciplined thinking founded on rationality and psychological maturity.

What this interpretation of the history of religion and science means is that modern science is seen as representative of the more efficacious aspects of human thought. But the Western, though problematic, view is that science, as we know it, is of Western provenance and that this, therefore, puts traditional systems of thought at an epistemological disadvantage. According to Horton, this is the position taken by the Symbolists who 'by their steadfast determination to interpret magic and religion as types of thought dedicated to the production and appreciation of symbolic imagery for its own sake, avoid this over-scientistic approach and duly transcend the Western perspective in which they were brought up' (1997: 129).

Horton's answer to what may seem to be an evident epistemological disparity in terms of yield on the one hand from scientific analysis and from traditional modes of thought that appeal to metaphysics for explanation on the other is that both the traditional and the modern share similar goals of explanation, prediction and control. This approach effectively deals with the idea that traditional and modern modes of thought are sufficiently distinct qualitatively to warrant the appellations of 'irrational' and 'rational' respectively. Thus one might argue that what Horton has achieved is as follows: he has offered cogent arguments against the old comparative paradigm formulated by Lucien Levy-Bruhl et al., that claimed that non-European traditional thought was 'primitive' and 'pre-logical' while modern thought founded on reason and scientific empiricism was epistemologically sound and pragmatically efficacious (Levy-Bruhl 1922). The principal aspect of so-called 'primi- 
tive' thought was emotion not ontological objectivity. It is interesting to note that in order to offer an alternative to what was perceived as the epistemological dominance of Western scientific rationality the Negritude school of thought of Senghor and Césaire positively embraced this dualistic paradigm. Horton's paradigm, no doubt, is opposed to this position.

\section{Qualitative epistemology: Primary and secondary theories}

Horton's continuity thesis relies to a great extent on the ideas of what he refers to as primary and secondary theory. Note parenthetically that modern philosophers of science speak of the 'observational' and the 'theoretical'. According to Horton primary theory may be applied transculturally hence intra-linguistically. The reason is that the empirical world presents itself in similar fashion to all humans in all cultures. As he puts it: 'Primary theory does not differ very much from community to community or from culture to culture. These differences notwithstanding, however, the overall framework remains the same. In this respect, it provides the cross-cultural voyager with his intellectual bridgehead' (1997: 321). In the case of secondary theory, however, matters become somewhat more problematic: the explanatory theories appealed to in traditional African metaphysics are qualitatively at variance with those in modern science. Recall that Horton's goal is 'to present a programme for the cross-cultural study of human thought systems.... Basic to this programme is the assumption of a strong core of human cognitive rationality common to the cultures of all places on earth and all times since the dawn of properly human social life. Central to this "common core" of rationality is the use of theory in explanation, prediction and control of events. Central too is the use of analogical, deductive and inductive inference in the development and application of theory' (1997: 343).

But the key question that Horton seeks to answer is as follows: 'How do we get from the "common core" of rationality to the dramatic differences which we observe between, for example, the styles and patterns of thought in sub-Saharan Africa and the styles and patterns in the recent West?' (1997: 343). Horton applies the same question to what he describes as the 'almost equally dramatic differences between twelfth-century and twentieth-century Western styles and patterns' (1997: 343). Horton's answer is that the "logic of the situation" dictates the use of different intellectual means to achieve the same ends' (1997: 343). In this regard, Horton tells us, the assumed epistemological opposition between the 'intellectualist' and 'sociological' paradigms of explanation is erroneous; both are complementary and mutually indispensable. But what is of importance is Horton's argument that the difference in yield between modern science and other modes of explanation does not derive from the 'superior rationality of Westerners' but rather from 
'universal rationality operating in a particular technological, economic and social setting' (1997: 343). According to Horton, this observation 'could have momentous implications for cross-cultural studies generally' (1997: 343). In sum, Horton argues for a 'universal rationality' not a 'superior Western rationality' as a more appropriate means of explaining the greater cognitive yield of modern science, which 'enables the egalitarian scholar to cast away his fear of invidious comparisons and look at non-Western theory with the eye of its user' (1997: 344).

Horton's argumentation here is problematic because on the one hand he speaks of a universal rationality and on the other he speaks of that kind of rationality as being appropriate for a particular technological setting. The implication is that this universal rationality would be appropriate for one technological setting but not for some other. If this is the case then we cannot properly speak of an inter-cultural universal rationality. The point is that universal rationality applied to all contexts would offer ontologically similar explanations in all cases. It follows logically that some explanations would be more efficacious regardless of context. The reason for this is that if universal rationality is acceptable at the level of primary quality on grounds of palpable evidence it should also be acceptable on the same grounds at the secondary level. The crucial distinction between the theoretical posits of the secondary theories of empirical science are expected to bear empirical evidence - directly or indirectly - at some stage of the explanatory narrative.

The theories of empirical science rely maximally on theoretical terms whose cognitive worth is determined by how much they refer to existent phenomena. Theoretical terms such as electrons, protons, neutrons, genes, and so on do not belong to primary theory according to Horton yet their confirmable empirical existence is vouched for according to publicly accessible experiments. Thus there is a direct causal link between the terms and concepts of primary theory and those of secondary theory in the case of empirical science. The application of logical rules such as modus tollens is important in this regard. In the case of traditional metaphysics this is just not the case. Repeatable instances of the public application of modus tollens and a recognition of what set of results would prove the theory untrustworthy are not assigned crucial importance. In this regard there is no requirement that a confirmable causal connection be established between primary and secondary theory. Horton's theory of universal rationality would seem to be inapplicable in this instance. It is on account of the requirement that there be epistemological commensurability between primary and secondary theory that renders problematic Horton's thesis about the appeal to universal rationality for both scientific and metaphysical thought. 
It is for this reason that physicists are still puzzled by the behaviour of matter at the quantum level as expressed by Heisenberg's uncertainty principle. Or consider Bohr's validated claim that the classical model does not apply to the world of elementary particles. Now Bohr just did not posit that claim. He engaged in a debate with Einstein about the causal structures of the quantum world that was to be settled by empirical test. But even if one of the results of quantum analysis is that observed or sensed reality results from a puzzling interaction between the observer and observed, the goal is to continuously seek new explanations by way of empirical test. This is not the case with traditional metaphysics. Because once established, the secondary theories in traditional metaphysics preserve a particular ontology which is not required to be tested against reality. A universal rationality cannot logically apply, therefore, to both kinds of secondary theory. Another observation is that any scientific theory gains its validity on the basis of two important phenomena: inductive inference and potential falsifiability. Inductive inference is the principle on which scientific theories and their constituent laws regularly describe the structure of reality. Metaphysical theories in general do not expose themselves to such. Similarly, a theory demonstrates its scientific credentials by formulating exactly how it could be invalidated. Again, metaphysical theory is not sufficiently well formulated to allow such. This would mean, therefore, that the mere fact that a particular theory appeals to a secondary theory does not constitute an adequate basis to place it on qualitative par with an empirically based scientific theory.

Yet there are scientists who are epistemologically comfortable with Horton's continuity hypothesis. Physicist Edgar Ascher in a discussion on Horton and Bohr (Asher 1990: 176) argues that there are certain similarities between traditional African thought and quantum mechanics. But again, I argue that there is a crucial difference between quantum mechanics and traditional African metaphysics in that researchers in the former field are not epistemologically comfortable with the anomalies and puzzles of quantum mechanics and work to resolve them by appeal to empirical evidence. Such is not the case with metaphysical theories.

\section{African science and the continuity thesis}

The implicit subtext of Horton's thesis is that he is seeking to make up for the Western belief that the West has established an important cultural differential between itself and the non-Western world - Africa especially - because it invented science. Horton's appeal to the idea of universal rationality and his claims about explanation, prediction and control - intrinsic to the scientific enterprise - being equally intrinsic to traditional African thought can be seen as his own coming to terms with the question he himself posed in 
this regard. Horton writes: 'Here, I think, we get close to the root of liberal sentiment. For is it not the inmost reason why the Western liberal feels compelled to allot the non-Westerner a special cognitive province a secret conviction that science can never really be the non-Westerner's "thing" (Horton 1997:102). This is also the basis for Horton's critique of both 'Symbolism' and 'Fideism'. Horton dismisses these two movements for lacking in intellectual conviction, but that 'They survive, not because they have any genuine interpretative value, but because they serve an ideological need: i.e. the need to place traditional religious thought beyond the range of invidious comparison with Western scientific in respect of efficiency in the realms of explanation, prediction and control' (Horton 1997: 307).

But I would want to disabuse Horton and others of this assumption about the West and the origins of science. He writes: 'In many ways, the rise of the scientific outlook makes a strange tale. It starts in the Greek overseas colonies during the sixth century B.C., continues first in Alexandria, then in Baghdad, then in southern Italy and Spain, then finally shifts to north-west Europe, the United States and the Soviet Union' (ibid: 101). An obvious point of critique here is that Japan should also be included on Horton's short diffusionist list. But the key point of criticism here is that science did not begin with the Greeks. In support of this Horton claims that science first began in the Greek overseas colonies and not in Greece proper. And although Alexandria was a colony of Greece, it was mainland Greece itself that absorbed scientific knowledge from Alexandria where the technological legacy of ancient Egypt was evident. For example, the important mathematical and scientific work that theorists such as Euclid and Heron carried out was done in Egypt and not in mainland Greece.

The idea that science (and logos in general) first began in Greece is an idea spread by most Western historians of science and other Western intellectuals. But consider this: Clearly, the Greek overseas colonies and Alexandria were not intrinsic parts of Greece itself. Science, properly defined, is merely an empirical search for the causal understanding of phenomena about which the researcher harbours an interest. In short, it is not much more than inquiry into the structures of reality and the principles that govern those structures. None of the present orthodox definitions and mystifications of science would contravene this observation about science in general. The claim that science is of particular Greek - hence putatively Western - origin is, on this basis, quite problematic. Science in its most general sense involves understanding natural processes in as dispassionately a manner as possible, without regard to non-empirical causes and effects.

In this regard the claims for a Greek origin of science cannot be upheld. The obvious evidence of the monumental ruins of the Egypto-Nubian culture 
complex points to some systematic knowledge of the laws of mechanics. This is supported by extant manuscripts in geometry and trigonometry. I refer to the Rhind and Moscow papyri for example. And in Plato's Phaedrus (274b especially) there is reference to the Egyptian invention of 'number and calculation, geometry and astronomy...' Perhaps it is for this reason that the historical evidence points to Athens as the centre of intellectual life for the Greeks while Alexandria was the locale for the diffusion of the scientific and proto-scientific ideas of the ancient Egyptians.

In further response to Horton's claim about the origins of science one might note that the ancient Egyptians also engaged in a systematic study of the stars before the Greeks. The ancient Egyptians observed the paths of stellar bodies empirically and sought to integrate the behaviour of these bodies into a general theory. It is on this basis that the sidereal calendar now in universal usage derives principally from the scientific theory of astronomy developed by the ancient Egyptians. Their pioneering efforts also in the area of the scientific study of human physiology are also noteworthy. One must recognise, of course, that the claim that the history of science should include its African phase would be viewed as problematic given the almost universally assumed priority ascribed to classical Greece. But opposing arguments by theorists such as Cheikh Anta Diop, who has marshalled strong evidentiary arguments in favour of Africa's position in the history of science, have already been made (Diop 1991). Relying on the research of scholars such as Paul Ver Eecke and V.V. Struve, together with the writings of the Greeks themselves, Diop makes a strong case for the thesis that the research efforts of the ancient Egyptians should be viewed as scientific (Diop 1991: 231307). Historian of science George Sarton was also convinced that the efforts of the early researchers in Ancient Egypt should be considered scientific. Consider the following: 'Some readers having at the back of their minds the prejudice that science is a Greek invention (have not scholars repeated that for centuries?) will insist and say "That may be science but not pure science." Why not?' (Sarton 1952: 49). Sarton then cites the remarks of a prominent Egyptologist, Henry Breasted, on the scientific structure of the Edwin Smith medical papyrus. Breasted is cited as describing the author (a surgeon) of the treatise and his successor as 'the earliest known natural scientists' (Sarton 1952: 49). But consider too Sarton's general assessment: 'To conclude, the Smith papyrus, and to a lesser extent the Ebers one, gives us a favorable idea of the idea of the medicine, anatomy, and physiology of the Egyptians, and the scientific outlook they had obtained at least two thousand years before Hippocrates' (Sarton 1952: 48).

We recognise that the essential feature of what we call science is inquiry into the structures of the natural world with the explicit goal of certifiable 
explanation. Accordingly then, the hallmark of scientific investigation is careful analysis expressed in objective language and strict measurement. In this regard, mathematics is of special importance. The scientific outlook of the Greeks would not have been grounded had it not been for its reliance on mathematics, the science of number and measurement. But Greek mathematics owed a debt to the mathematics of the Egyptians. Sarton himself writes of the pioneering work done by the Egyptians as part of 'the millenary efforts of Africans and Asians' (Sarton 1936: 9) that was later passed on to the Greeks who later located their centre for research in mathematics in Alexandria. Sarton writes: 'Thus was their debt to Egypt abundantly repaid by the Greek masters and their Roman disciples' (Sarton 1936: 9).

But the scientific outlook was not limited to Ancient Egypt only. Ancient Nubia during the era of Kush (Napata and Meroe) became know for its technology of iron smelting and metal work. Given the cultural relatedness and physical proximity of Ancient Nubia to Ancient Egypt it would follow that both areas shared similarities in technology and the scientific outlook. But iron technology, glass making and medical practices and their requirement of an implicit scientific outlook are not to be limited to the Egypt-Nubia complex but also to extensive areas of Africa much further South (Diop 1987: 196-211). It is a fact that the relatively complex iron smelting employed by some African societies was often performed within the context of metaphysical assumptions but this should not detract from the claim that in terms of the actual empirical practices the scientific intent was evident (de Barros 1997: 132-149). One should recall too that scientific research in Europe before its modern expression was often accompanied by considerations that appealed to the occult (Seligman 1948: 482).

Thus the idea that science is strictly of Western origin is problematic as I have stated. It is in this historical regard that Horton's continuity and similarity theses are to be understood. The point is that African thought has produced a continuous progression from a metaphysical epistemology and ontology to one that has become increasingly empiricist over time. Horton's major claim in the general corpus of his writings, we may recall, is as follows: 'if there is one thesis that unites the essays assembled in this volume, it is that of the deep-seated similarity between much of the world's religious thought, past and present, and the theoretical thought of the modern sciences' ('Postscript', 347). But what Horton should have mentioned is that there is evidence for practical-cum metaphysical thought in pre-modern African societies all the way up to what is now regarded as the beginnings of scientific thought. One can argue with confidence that the idea of 'science' in Greece was not the end product of a continuous stream of mutational thought that was indigenous to Europe. As mentioned above, Horton fails to 
distinguish between metaphysical thought which sought to explain empirical phenomena by appeal to non-verifiable causes, and metaphysical thought whose function was to establish modes of communication between humans and personalised, idealised or spiritual entities whose abode was a non-empirical world. These modes of communication were established principally then on moral considerations.

There is indeed a similarity of intent between pre-scientific causal metaphysics and modern science in that both paradigms seek the explanation, prediction, and control of sensed phenomena, but matters are different in the case of religion whether major or otherwise. The interaction between humans and their gods is personal and geared towards communion. The communion is essentially based on moral principles and without much consideration granted to explanation, prediction and control - except in a very general way.

The implication of what is argued for in this instance is that it really is not necessary to argue for qualitative similarities between traditional African religion and Western science to prove epistemological continuities between the two modes of thought. Religious thought is no more the essence of African modes of thinking than scientific thought is that of the West. More appropriate comparisons would be between European traditional-cum-religious thought and Western science. Similar considerations apply to modes of thought in Africa. Human interaction with empirical nature has always been driven by a pragmatic need to master the environment. Metaphysical explanations were sought for phenomena that could not be explained by appeal to the pragmatic. Increasing success in the explanation of phenomena by appeal to the empirical led ultimately to the weakening of the cognitive acceptability of metaphysical theory. The ultimate defeat of metaphysics in seventeenth century Europe must necessarily be traced back to the practical and empirical thought that served as the prototype for the development of tool technology in Africa in general and the development of proto-scientific and scientific thought in the Egypto-Nubian complex. The same may be said about the meaning of modern religious thought of the monotheistic variety and traditional African religions. Both are merely versions of what some anthropologists refer to as 'ancestor worship'.

\section{Relativism, foundationalism, and Horton's thesis}

What distinguishes philosophical inquiry historically from other disciplines is that it is constantly wrestling with issues of epistemology - the perennial problem of establishing the appropriate criteria for separating genuine knowledge, truth, the facts, and its cognates from what appear to be such. I would not attribute these cognitive concerns specifically to ancient Greek philoso- 
phy but rather to the nature of human consciousness as embedded in human languages. Every human language must necessarily include not only concepts of truth and falsity but also epistemological criteria for determining such. But important constraints exist in determining whether established truthdetermining criteria are adequate or whether they are being adequately applied. At the level of primary theory where phenomena are easily observed and claims about such confirmable, matters are not very problematic. In any language a proposition such as 'I have five cows on my farm and I want to sell them' is an empirical claim whose truth status is easily confirmable. But epistemic problems arise when claims about phenomena are made but are not easily confirmable.

The importance of science derives from the fact that human consciousness recognises that sensed phenomena are complex and may be examined in diverse ways. Primary theory, according to Horton, tells us for instance that colours are macroscopic appearances but the secondary theory of scientific research informs us that they are light rays of particular wavelengths on the visible spectrum. As we see, the science-philosophy problematic is in reality just another way of examining the old 'appearance-reality' problematic. The question here is this: just how successful could the enterprise of ontology be under the guidance of scientific investigation? Scientists are quite confident that their discipline is best equipped to answer this question and as a result place little confidence in the results derived from metaphysical research. Despite the crucial necessity of deductive thinking, theories must ultimately be tested against reality if the ontological question is to be solved.

One of the problems with Horton's continuity thesis is that whenever novel ontological claims are seen to be at scientific variance with predicted outcomes, cognitive anomalies are immediately recognised. Concerted efforts are then embarked on to save the theory. In terms of primary and secondary theory there is an epistemologically unacceptable disjunction between the empirical claims of primary theory and the putatively theoretical constructs of secondary theory.

But this kind of consideration does not apply to scientific theory since there is no epistemological obligation to vouch for the existence of entities circumscribed by secondary theory unless they are at least testable in principle. So universal rationality cannot apply in both cases. The paradox with Horton's epistemology is that it is intrinsically relativist while claiming to be universalistic. The reason is that it is only on relativist grounds that one could claim that primary and secondary theories in scientific and metaphysical thought are equally valid. The point is that for empirical science reducibility in principle is supposed to hold for primary and secondary theory. It is in this 
realm alone that universal rationality is assumed to hold. But Horton is not a cognitive relativist.

Note in this connection that it was Kuhn who argued for a theory of cognitive relativism with the claim that science progresses not by adherence to some principle of universal rationality but by cultivating research paradigms that might be cognitively incommensurable. Kuhn's research proved to be highly controversial given that many theorists saw his work as being founded on epistemological relativism which was seen as incompatible with genuine scientific research. Kuhn's theory meant for epistemology that the ontological quest for foundations was questionable. But his theory did not stand alone: Kuhn's theoretical approach became an intrinsic part of a novel cognitive movement. His ideas were soon to be complemented by the more pronounced epistemological relativism of Paul Feyerabend's Against Method (Feyerabend 1975) and in the area of philosophy proper by the work of Richard Rorty (Rorty 1980). For Rorty, the perceived soundness of a theory was a function purely of its contextual moorings. The question concerning the strength of a theory was to be determined only by its pragmatic yield. In other words the 'truth' of a claim or theory was not to be determined according to some universal rationality but according to the epistemological criteria set by the theory itself. In this regard Horton is on an ontological par with Rorty and Kuhn.

But there is a crucial difference. Epistemological relativists eschew the idea of a universal rationality whereas Horton does not. There is an obvious reason for this. Horton's research involves making judgments on modes of inter-cultural thought. His attempts to inject cross-cultural translatability into different paradigms of thought would no doubt flounder were he to embrace the relativist epistemology of a Kuhn or a Feyerabend. Such a move would place him epistemologically on par with theorists such as Levy-Bruhl and Evans-Pritchard in their analyses of African modes of thought which, of course, was not his intention. It was on this basis that he saw fit to narrow an assumed epistemological gap between African metaphysical (including religious) thought and modern scientific modes of inquiry with the positing of the idea of an universal rationality. Horton's thesis is correct in one sense but erroneous in another. He is correct in assuming that human thought - a function of an environmentally shaped central nervous system - confronts the sensory world not only empirically but also causally. Whenever possible, explanations of phenomena are sought on the basis of empirical causation. But it should be noted too that when empirical explanations are not forthcoming human thinking has the tendency to seek next best explanations by appeal to the metaphysical. But in resorting to this modality of explanation empirically certifiable causal chains are given short shrift. The saving grace is that as technology develops and permits empirically more certifiable causal 
explanations, metaphysical explanations are increasingly replaced. And this gradual transformation has taken place at all levels in Africa and other areas.

But this brings me to the interesting debate that Horton engages in as he compares the epistemological paradigms of Levy-Bruhl and Durkheim, both of which are central to Horton's own analysis of culturally derived modes of thought. Horton has embraced what he refers to as the continuity/evolutionary schema in contradistinction to the contrast/inversion schema embraced by theorists such as Levy-Bruhl. For theorists such as Levy-Bruhl, traditional pre-modern thought was essentially founded on a non-rational epistemology. Modern thought by contrast derived from rational, empirical and logical considerations. And it was this approach that made scientific investigation and rational thought possible. The evolutionary process therefore was as follows: as scientific knowledge accumulates non-rational beliefs are increasingly given up. But this evolutionary process requires radical epistemological changes because the two modes of thought are incommensurable. According to Horton, Durkheim partook of this methodology in his contrasting of what he regarded as modes of thought characteristic of the 'sacred' and of the 'profane'. It is in this connection that Durkheim and Levy-Bruhl are epistemologically on a par. Yet Horton claims that Durkheim also argued for a common epistemological grounding for both pre-modern metaphysical thought - religious or otherwise - and scientific thought in that both modes of thought sought explanation of sensed phenomena by appeal to non-empirical theoretical considerations (Horton, 1997: 72). Horton cites Durkheim favourably with the following: 'Thus between the logic of religious thought and the logic of scientific thought there is no abyss. The two are made up of the same elements, though inequally and differently developed' (Horton 1997: 72). For Horton this is evidence that Durkheim supported the continuity/ evolution paradigm. Thus, according to Horton, 'although there is recognizably one Levy-Bruhl, there are at least two Durkheims. In choosing which Durkheim to use in the comparison, I have been guided by the master's own opinion. Nevertheless, we should not forget that, in some of Durkheim's remarks about the sacred and profane, there is implicit a contrast/inversion which is difficult if not impossible to reconcile with the evolutionist main line in his thought, and which is reminiscent of Levy-Bruhl' (Horton 1997: 78-9).

But this seeming problematic is easily resolved according to the thesis for which I argue. Human thought historically may be understood as consisting of two main categories: empirically confirmable thought and metaphysical thought. Empirical science with its commitment to explanatory analysis that must be grounded in the empirical world belongs to the same category as the profane whether in the case of the pragmatic thinking of pre-modern 
villagers or that of the laboratory-bound scientist. Metaphysical thinking consists of two sub-categories, one of which has developed into religion and other into a kind of ersatz science. It is on these grounds that the contrast/ inversion model finds its limitations. The reason is that it is not viewed as anomalous for a contemporary Westerner to be thoroughly schooled in modern physics yet practice and be affiliated with a set of religious doctrines that require suspension of critical rationality in favour of religious faith. A ready proof is afforded by the West itself where Jesuit priests at academic institutions are practicing physicists. Assumedly, they pray regularly and have communion with their personalised deity. Yet such individuals would not accept the existence of substances such as the ether or phlogiston. And again I argue in opposition to Horton that the continuity/evolution theory would apply only to the non-religion part of general explanatory theory. And this is so simply because although religious theory seeks ultimate explanation it distinguishes itself from the other section of metaphysics in that it seeks contact and communion with departed ancestors or godheads.

In this regard the position taken by the 'Fideists' concerning religion does have merit. Horton states that 'much hot ink has been directed against my thesis of a basic continuity of structure and intention as between traditional religious and modern scientific thought' (Horton 1997: 306). For the 'Symbolists' religious life is to be understood as 'a species of poetic jollification rather than as a system of theory and practice guided by the aims of explanation, prediction and control' (Horton 1997: 306). For the Wittgenstein 'Fideists' religious life amounts to the 'expression of an autonomous commitment to communion with Spiritual Being, and again as something totally different from thought and action directed by the ends of explanation, prediction and control' (Horton 1997: 306).

The fundamental problem here is this: despite the fact that those who adhere to particular religions do seek ultimate explanation for the existence of phenomena in general, they seek this explanation in terms of interactive communion. The beings communicated with are necessarily anthropomorphised. This is not the case basically with empirical and scientific inquiry. The ultimate goal is to seek the explanation of the existence and behaviour of phenomena assumed to be inanimate purely in terms of causal laws and principles. It is in this regard that the contrast/inversion and continuity/evolution paradigms collapse into each other. Pre-modern science involved empirically untenable assumptions such as vis viva, entelechy and so forth. In many cases, theoretical constructs were simply assumed without confirmable empirical evidence. But a continuous evolution was guaranteed in the progress of science by the stubborn adherence to the principle that the empirical world alone 
could afford cognitively satisfying explanations. The same empirical principle that leads a pre-modern farmer to confirm the number of cows in his possession by counting them then seeking empirical explanations if any are missing is the same principle that drives empirical science along its evolutionary path as it necessarily discounts un-confirmable metaphysical claims. This process involving both inversion and evolution does not apply to religious practice.

What also constitutes an important differential between religious practice and scientific investigation is that the former is often a marker of social and group identification that adherents conform to mainly on cultural grounds. A society where participation in a regular religious practice is the norm would tend to confer outsider status on non-conforming individuals. The social costs to epistemologically sceptical individuals may just be unacceptable; so they outwardly conform to the practice. Kuhn (1962) pointed out that this kind of socio-anthropological behaviour is also common among differing scientific research paradigms but the crucial consideration is that the goals of scientific research ultimately override the emotively founded kinship networks established whenever cultural practices develop.

\section{A retrospective note}

In recent times the intellectual appraisal of Africa and its peoples by research scholars has been different from similar appraisals elsewhere in the sense that it has been rather deficient in self-appraisal. This has not been the case with Europe and parts of Asia. Europe has long engaged in its own selfappraisals ever since it adopted the Mesopotamian and Ancient Greek intellectual traditions. The same applies to parts of Asia, especially China with its intellectual self-appraisals according to the reflections of writers such as K'ung Fu-tzu (Confucius) and Lao Tsze. The West's appraisal of China does not stand on its own. It must be taken in conjunction with China's own intellectual self-appraisals. Matters are somewhat different in the case of Africa. On account of historical contingencies, Africa's self-appraisal in the form of the intellectual efforts of, say, Ancient Egypt and Nubia, Plotinus, Augustine, Ibn Khaldun, Ahmed Baba, Timbuktu scholars such as Kati and Sadi, Zara Yacob, etc., has not been much established as elements of an history of ideas. The more popular intellectual appraisals of Africa are those that have been produced within the context of the European colonial paradigm. Hence Placide Tempels and E.E. Evans Pritchard are much better known for their 'other' appraisals of Africa than the appraisals of an Ahmed Baba or a Plotinus. Thus any self-appraisal of African thought that accurately describes Africa's intellectual history over time must require a different autonomously generated conceptual framework. This is what occurred in the case of Europe. The 
Western history of ideas is one that has been constructed to include not only the intellectual history of the Greeks but also those of the Romans who extended their civilisation to most parts of Europe. But the official Western history of ideas does not include a Celtic or Gallic traditional thought or ethnic philosophy. Instead, Greek thought - by no means sui generis with its adapted influences from Ancient Egypt and Mesopotamia - is posited as the catalytic point of departure for Western thought. And yet the Greeks had no conception of the historic role they would play in the development of the intellectual history of the West.

The appraisal and development of African thought, both 'traditional' and modern, need not travel the route of a search for 'gnosis' or alternative modes of thought as suggested by theorists such as Mudimbe (1988) and others. The truth is that human thought began in Africa and its products were exactly those that we have today: the empirical, the metaphysical, and the axiological. This has been the intellectual patrimony handed down to all of humanity. The thinking that produced the implements of the African Palaeolithic and Neolithic is the same kind of thinking that produced modern thought in all its dimensions.

Metaphysics entered the human intellectual landscape because what the human mind could not certify and explain empirically was shunted over into the thought realm of the imagination. Thus there are no African or human modes of thought which do not partake of the empirical, the metaphysical and the evaluative. Practical technology is the forerunner of empirical science as we know it today. And as mentioned above, this has been Africa's intellectual contribution to world civilisation. As Horton has argued, there is just one continuous epistemological line stretching from African traditional thought to modern science. The truth is that there is no epistemological tradition that has sprung up independently in the West. Its mutational roots - like those for all of humanity - go straight back to the African causal modes of thinking described by Horton and not those of the quasi-essentialist varieties described by Tempels, E.E. Evans-Pritchard and J. Mbiti.

In the final analysis humans assign less practical value to esoteric modes than to those modes of thought that produce empirical and technological knowledge. Humans in Africa and elsewhere are more appreciative, in practical terms, of the theoretical and empirical knowledge that yielded the world's first technologies such as witnessed by the Neolithic, the Iron Age, the Agricultural Age and the Modern Age.

The same may be said for other important dimensions of human thought such as those involving the evaluative judgments of ethics and aesthetics. This kind of thinking is also a direct product of fundamental African thought. The belief that there is something qualitatively distinctive about African 
thought or that there is something essentialist about pre-modern African thought is, therefore, erroneous. The architecture of the modern human brain was set in place ever since humanity in Africa developed abstract thought, speech, and variable technologies. Contemporary research in anthropology has yielded the reasonable hypothesis that behaviourally modern humanity began in Africa (Macbrearty and Brooks 2000: 453-563). This would imply that all aspects of modern human thought have their foundations in African thought. Thus the lingering belief that African modes of thought are essentially more affectively impressionistic than epistemological and that Western epistemologies are sui generis and derive possibly from a different cerebral architecture is quite problematic. The point is that human modes of thought are strictly determined by the existing environment with its culture-specific technologies and knowledge bases.

There are those who believe (anonymous referees, for example), that the perceived distinctiveness of the different human languages suggests qualitatively distinct epistemologies. But all human languages are artificial and spring from the abstractive and constructive qualities of the human mind, which must begin its operations in the materiality of the sensory world. Disputations about different epistemologies and their supposedly qualitative independences are thereby rendered moot on account of the flexibility and inter-translatability of all human languages on all matters empirical. It follows from this that there is no epistemological tradition that originates in the West that does not derive from a prior universal epistemology that has its roots in the thinking processes of the first humans in Africa.

\section{Conclusion}

The explicit function of anthropology as an invented discipline was to study and evaluate the customs and modes of thought of non-European peoples. Cultures studied under the rubric of cultural anthropology had a physiological correlate in the study of the brain structures of physical anthropology. But the research goal of cultural anthropologists was to analyse and solve the problem of the evolution of human thought. This was the question that engendered the dynamic of discussion engaged in by European theorists such as William Wundt, Levy-Bruhl, James Frazer, Claude Levi-Strauss, E. E. Evans-Pritchard, Franz Boas and others. The fundamental question always was the relationship between modern Western thought implicitly viewed as developed and rational and non-Western thought seen as less developed. Horton's function in this history of Western anthropology was to attempt to debunk the cognitive incommensurability thesis between traditional nonWestern modes of thought and those of the modern West. Witness in this regard Horton's critique of Winch (Horton 1997: 138-160). 
Horton's main point is that African traditional modes of thought and Western modes are qualitatively cognate and epistemologically commensurable. Thus African modes of thought and Western modes of thought are to be understood as operationally identical in terms of explanation, prediction and control. The cognitive processes here were to be understood in terms of a kind of epistemological equality between Western science and African traditional thought. This was explained in terms of Horton's primary and secondary theories. At work here was what Horton labelled 'universal rationality'. Yet there was a crucial differential: the West invented and partook of the scientific wing in the cognitive structures of universal rationality. It is on this crucial point that I argued that this partition was problematic. If one were to retain the idea of universal rationality one could argue that one portion would justify itself according to what one might refer to as 'cognitive ontology' while the other portion could be labelled 'heuristic rationality'. Cognitive ontology would refer specifically to confirmable scientific theory and heuristic rationality would apply to explanations offered that could not be similarly confirmed.

The foundations and expressions of such could be found both in historical Western and African thought. Thus all levels of universal rationality - in the sense of the human need to explain phenomena - were to be found in the history of African modes of thought whether religious, magical or scientific. I argue that religious discourse is essentially not about prediction, explanation and control but about communion and interaction with metaphysical entities. Since there is an African history of science and technology the comparison between African traditional thought and Western science is thereby rendered unnecessary.

The problematic of interpretation originally developed because - unlike in the West - there has not been a constructed tapestry linking together the different stages of Africa's intellectual efforts. This gives the impression of an uneven, restricted and truncated African intellectual history. It is on this basis that attempts to establish the contours of modern African thought invariably sought their groundings in some Western school of thought. Consider in this regard the holistically metaphysical groundings provided by LevyBruhl, and Placide Tempels for Negritude (Senghor and N'Daw), Ethnophilosophy (Mbiti), and African dynamic materialism (Hountondji). By appeal to a broader, more historical, model of African historical selfconsciousness, it becomes more possible to evaluate the ideas on African thought as expressed by the various theorists operating from within the Western intellectual tradition. 


\section{Bibliography}

Ascher, E., 1991, 'Modes de pensée: L'universel dans le particulier', in Yvonne Preiswerk and Jacques Vallet, eds., La Pensée métisse, Paris: Presses Universitaires de France.

De Barros, P., 1997, 'Ironworking in its Cultural Context', in Joseph Vogel, ed., Encylopedia of Precolonial Africa, Walnut Creek, California: Altamira Press. Diop, C.A., 1991, Civilization or Barbarism, New York: Lawrence Hill Books. Evans-Pritchard, E. E., 1937, Witchcraft, Oracles and Magic among the Azande, Oxford: Clarendon Press.

Evans-Pritchard, E. E., 1956, Nuer Religion, Oxford: Clarendon Press.

Feyerabend, P., 1975, Against Method, London: New Left Books.

Frazer, J.G., 1967, The Golden Bough, London: Macmillan.

Horton, R., 1997, 'A Definition of Religion and its Uses', in Robin Horton, ed., Patterns of Thought in Africa and the West, Cambridge: Cambridge University Press.

Horton, R., 1997, 'African Traditional Thought and Western Science', in Robin Horton, ed., Patterns of Thought in Africa and the West, Cambridge: Cambridge University Press.

Horton, R., 1997, 'Back to Frazer', in Robin Horton, ed., Patterns of Thought in Africa and the West, Cambridge, Cambridge: Cambridge University Press.

Horton, R., 1997, 'Levy Bruhl, Durkheim and the Scientific Revolution', in Robin Horton, ed., Patterns of Thought in Africa and the West, Cambridge, Cambridge University Press.

Horton, R., 1997, 'Postscript', in Robin Horton, ed., Patterns of Thought in Africa and the West, Cambridge: Cambridge University Press.

Horton, R., 1997, 'Tradition and Modernity Revisited', in Robin Horton, ed., Patterns of Thought in Africa and the West, Cambridge: Cambridge University Press.

Kuhn, T., 1962, The Structure of Scientific Revolutions, Chicago: The University of Chicago Press.

Levy-Bruhl, L., 1910, Les fonctions mentales dans les societés inférieures, Paris: Alcan.

Levy-Bruhl, L., 1922, La mentalité primitive, Paris: Alcan.

McBrearty, S. and Brooks, A.S., 2000, 'The Revolution that Wasn't: A New Interpretation of the Origin of Modern Human Behavior', Journal of Human Evolution 39.

Mudimbe, V. Y., 1988, The Invention of Africa, Bloomington: Indiana University Press.

Rorty, R., 1980, Philosophy and the Mirror of Nature, Princeton: Princeton University Press.

Sarton, G., 1936, The Study of the History of Mathematics and the Study of the History of Science, New York: Dover Publications.

Sarton, G., 1952, A History of Science, Cambridge: Cambridge University Press. Seligman, K., 1948, History of Magic, New York: Pantheon Books. 
